\title{
Optimization of the Surface Roughness Equation obtained by Al7136 End-Milling
}

\author{
Alina Bianca Pop ${ }^{1, *}$ and Mihail Aurel Țîțu ${ }^{2}$ \\ ${ }^{1}$ SC TechnoCAD SA, Vasile Alecsandri no. 72, code 430351, Baia Mare, România \\ ${ }^{2}$ Lucian Blaga University of Sibiu, Victoriei Street no. 10, code 550024, Sibiu, România
}

\begin{abstract}
The aim of this paper is to optimize the regression equation of the surface roughness obtained by 7136 aluminium alloy machined by endmilling process. The surface roughness is dependent on certain process parameters, which can vary, causing in this way variations of the surface quality. The research method used in this paper is the experiment and the Taguchi design of experiment. The experiment was performed using an experimental stand, in which every step to get the purpose, is presented. The measurements were made using a portable surface roughness tester. In the first part of the paper the influence percentage of the involved parameters in the machining process, was determined. Then, a multiple linear regression model, in three different ways, was realised, in order to optimise the predicted regression equation that was initially proposed.
\end{abstract}

\section{Introduction}

Surface roughness greatly influences the performance of mechanical parts, as well as the production cost, therefore, it is a very important measurement of the product quality. Also, the surface roughness has a great impact on the mechanical properties, like: fatigue behaviour or corrosion resistance, and functional attributes like: wear, friction, light reflection, heat transmission, and electrical conductivity. Currently, there have been many research developments in surface roughness modelling and optimization of the metal cutting process parameters, to obtain the desired surface finish, since only the proper selection of these parameters can produce a better surface finish [1]. About the previous researches, the surface roughness was studied in different research papers, in which the experiment and the mathematical and statistical methods were adopted. For example, in [1] and [2] the 7136 aluminium alloy used in the aircraft industry was studied by end milling process to analyse the cutting feed effect on the surface quality and the manufacturing time reduction, using standard tools for aluminium machining. A mathematical modelling of the surface roughness resulted by the end milling process of Al7136, depending on the cutting process parameters studied in a settled experimental field, was determined in [3]. In this paper, using the variance analysis ANOVA, the degree of confidence for the achieved results by the regression equation was determined, and the suitability of this equation on

\footnotetext{
* Corresponding author: bianca.bontiu@gmail.com,
} 
every point of the experimental field. In [4] the author purpose was to highlight the importance of Taguchi's method use to analyse the surface roughness of 7136 aluminium alloy in end milling process. In this paper, the attention will be focused on the Taguchi design of experiments - method steps presented in [5] and [6]. Then, to determine the equation who describes the surface roughness values according to the process parameters it is necessary to realised some practical experiments to determine the values of surface roughness for different set-up values of cutting process parameters. Using the obtained data, a linear regression model will be determined to describe the studied process. A similar research made on this direction is [7]. Finally the regression model will be optimised to increase the degree of prediction for this model.

\section{The experiment}

First, to get this research paper purpose, it is necessary to obtain the data that has to be processed - the surface roughness measurements. For this, the experimental stand used to perform the experiment, is presented in figure 1.

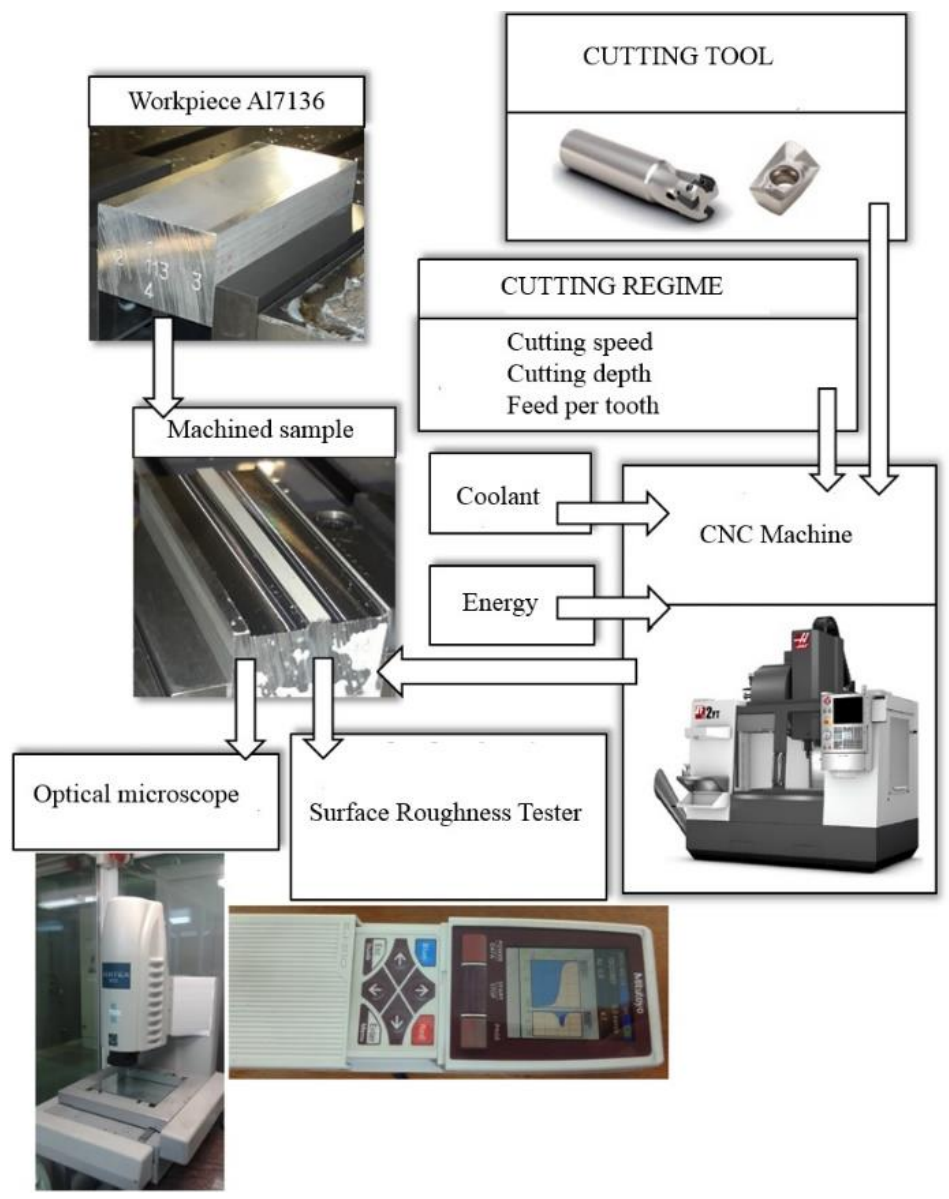

Fig. 1. The experimental stand [8].

As it can be seen here, first the workpiece material is chosen - the Al7136 aluminium alloy. The behaviour of this material will be studied in accordance with the proposed objectives taking into account the variation of the cutting regime parameters. The 
experiment will be performed using a standard tools set of aluminium machining - $16 \mathrm{~mm}$ End milling cutter with 100\% tool engagement - SECO R217.69-1616.0-09-2AN, holding two indexable cutting inserts XOEX090308FR-E05, H15. The machine used on milling tests is HAAS VF2 CNC. To make an optical determination and evaluation of the finished surface, the optical microscope Micro-Vu VERTEX 310 was used. To analyse the surface roughness for different machining conditions it was used the portable surface roughness tester - Mitutoyo SURFTEST SJ-210. After the experimental stand presentation the research methods used in this paper may be approached. For the beginning, the Taguchi's Method will be used to determine the parameters percentages and their interactions influence exerted on the surface roughness.

\section{The research methodology}

The research method of this study is the experiment. Then to determine the Ra values of the surface roughness obtained by Al7136 end-milling, the Taguchi design of experiment is used. Well, to determine the surface roughness, it is necessary to set up the experimental domain. The cutting process involves a series of cutting parameters. By all of these parameters, in order to achieve a good surface roughness in this paper the attention will be focused especially on the cutting speed $[\mathrm{m} / \mathrm{min}]$, cutting depth [mm] and feed per tooth [mm/tooth]. The values of the cutting regime parameters are chosen in accordance to the SECO Tools manufacturer indications and also according to the technological possibilities of the cutting tool, cutting inserts and CNC machine.

Table 1. The cutting regime according to the tools manufacturer indications.

\begin{tabular}{|c|c|c|}
\hline Cutting speed [m/min] & Cutting depth $[\mathbf{m m}]$ & Feed per tooth [mm/tooth] \\
\hline 495 & 2 & 0.04 \\
\hline 530 & 2.5 & 0.06 \\
\hline 570 & 3 & 0.08 \\
\hline 610 & 3.5 & 0.11 \\
\hline 660 & 4 & 0.14 \\
\hline
\end{tabular}

But, according with the Taguchi's method, the cutting process parameters gets the levels of minimum and maximum values. These levels are presented in table 2.

Table 2. The cutting process parameters and their values according to the Taguchi's Method.

\begin{tabular}{|c|c|c|c|}
\hline Abbreviation & Parameter & Level 1 (minimum) & Level 2 (maximum) \\
\hline A & Cutting speed & 495 & 660 \\
\hline B & Cutting depth & 2 & 4 \\
\hline C & Feed per tooth & 0.04 & 0.14 \\
\hline
\end{tabular}

Corresponding to these 3 established parameters and their third degree interactions, after the Taguchi method applying, it result the L8 $\left(2^{3}\right)$ orthogonal array. Well, it is necessary to conduct 8 experiments according to the Taguchi design of experiments. For each of these 8 experiments, three sets of the surface roughness measurements were made, which are presented in table 3 . 
Table 3. The measured surface roughness according with the parameters set.

\begin{tabular}{|c|c|c|c|c|c|c|c|}
\hline \multirow{2}{*}{$\begin{array}{c}\text { No. } \\
\text { of exp. }\end{array}$} & \multicolumn{2}{|c|}{ Parameter } & \multicolumn{3}{c|}{ Surface roughness measurements $[\boldsymbol{\mu m}]$} & \multirow{2}{*}{$\mathbf{R}_{\mathbf{a} \text { med }}$} \\
\hline & $\mathbf{A}$ & $\mathbf{B}$ & $\mathbf{C}$ & $\mathbf{R}_{\mathbf{a} 1}$ & $\mathbf{R}_{\mathbf{a} 2}$ & $\mathbf{R}_{\mathbf{a} 3}$ & \\
\hline 1 & 495 & 2 & 0.04 & 0.209 & 0.229 & 0.203 & 0.214 \\
\hline 2 & 495 & 2 & 0.14 & 0.235 & 0.231 & 0.238 & 0.235 \\
\hline 3 & 660 & 4 & 0.04 & 0.511 & 0.551 & 0.571 & 0.544 \\
\hline 4 & 660 & 4 & 0.14 & 0.515 & 0.512 & 0.504 & 0.515 \\
\hline 5 & 495 & 4 & 0.04 & 0.191 & 0.195 & 0.209 & 0.198 \\
\hline 6 & 495 & 4 & 0.14 & 0.210 & 0.221 & 0.223 & 0.218 \\
\hline 7 & 660 & 2 & 0.04 & 0.502 & 0.557 & 0.540 & 0.533 \\
\hline 8 & 660 & 2 & 0.14 & 0.715 & 0.712 & 0.740 & 0.722 \\
\hline
\end{tabular}

\section{The determination of the process parameters contribution}

To calculate the contribution of the cutting process parameters and their interaction, the measurements presented in table 3 are used. Using the Taguchi's method itinerary, the Variance analysis was adopted to determine the influence of the studied parameters exerted on the surface roughness. Using Minitab 17, in table 4 is presented this analysis.

Table 4. The Variance Analysis ANOVA (Minitab 17).

\begin{tabular}{|c|c|c|c|}
\hline Source & $\begin{array}{c}\text { DF } \\
\text { (degree of freedom) }\end{array}$ & $\begin{array}{c}\text { SS } \\
\text { (sum of square) }\end{array}$ & Contribution \\
\hline Regression & 7 & 1.554 & $99.99 \%$ \\
\hline A & 1 & 1.404 & $90.35 \%$ \\
\hline B & 1 & 0.044 & $2.85 \%$ \\
\hline C & 1 & 0.000 & $0.00 \%$ \\
\hline A x B & 1 & 0.066 & $4.30 \%$ \\
\hline A x C & 1 & 0.013 & $0.85 \%$ \\
\hline B x C & 1 & 0.002 & $0.17 \%$ \\
\hline A x B x C & 1 & 0.023 & $1.48 \%$ \\
\hline Error & 1 & 0.000 & $0.01 \%$ \\
\hline Total & 8 & 1.554 & $100.00 \%$ \\
\hline
\end{tabular}

In table 4 , it can be seen that 2 parameters and 3 interactions have a significant contribution with an influence exerted on the surface quality for the established experimental domain: the parameter $\mathrm{A}$ - cutting speed, the parameter B - cutting depth and the interactions between A x B - cutting speed with cutting depth and A x C - cutting speed with feed per tooth, and the interaction between all of three parameters A x B x C - cutting speed with cutting depth and feed per tooth.

\section{The regression equation determination of the process surface roughness}

Based on the table 4 results, the next step is to determine the regression equation of the surface roughness obtained under the cutting process parameters influence. For this, will be used only the parameters and the interactions previously set, that have the greatest influence on the surface quality. Using Minitab 17 software, the multiple linear regression model of the surface roughness for the Taguchi's method was determined, as it is shown in equation 
1. This multiple linear regression model was obtained without using the Box-Cox transformation. The Variance analysis of this equation is presented in table 5.

$$
R a M=0.000508 \cdot A-0.2499 \cdot B+0.000467 \cdot A \cdot B+0.00412 \cdot A \cdot C-0.00107 \cdot A \cdot B \cdot C
$$

Table 5. The Variance Analysis ANOVA of the regression model without Box-Cox transformation.

\begin{tabular}{|c|c|c|c|}
\hline Source & $\begin{array}{c}\text { DF } \\
\text { (degree of freedom) }\end{array}$ & $\begin{array}{c}\text { SS } \\
\text { (sum of square) }\end{array}$ & Contribution \\
\hline Regression & 5 & 1.526 & $98.14 \%$ \\
\hline A & 1 & 1.404 & $90.35 \%$ \\
\hline B & 1 & 0.044 & $2.85 \%$ \\
\hline A x B & 1 & 0.063 & $4.08 \%$ \\
\hline A x C & 1 & 0.005 & $0.37 \%$ \\
\hline A x B x C & 1 & 0.007 & $0.50 \%$ \\
\hline Error & 3 & 0.028 & $1.86 \%$ \\
\hline Total & 8 & 1.554 & $100.00 \%$ \\
\hline
\end{tabular}

The regression statistics of the equation (1) are:

- R squared: $98.14 \%$;

- R squared adjusted: 95.04\%;

- and R squared predicted: $87.76 \%$

Now, to optimise this equation (1), it is necessary to use the Box-Cox transformation with rounded $\lambda$. The resulted regression model is presented in the equation (2):

$$
\ln R a M=-0.00198 \cdot A-1.330 \cdot B+0.002310 \cdot A \cdot B+0.0071 \cdot A \cdot C-0.00174 A \cdot B \cdot C
$$

In table 6 is presented the ANOVA analysis of the regression model (2).

Table 6. The Variance Analysis ANOVA of the regression model with rounded $\lambda$.

\begin{tabular}{|c|c|c|c|}
\hline Source & $\begin{array}{c}\text { DF } \\
\text { (degree of freedom) }\end{array}$ & $\begin{array}{c}\text { SS } \\
\text { (sum of square) }\end{array}$ & Contribution \\
\hline Regression & 5 & 1.362 & $96.55 \%$ \\
\hline A & 1 & 7.456 & $69.48 \%$ \\
\hline B & 1 & 0.720 & $6.71 \%$ \\
\hline A x B & 1 & 2.140 & $19.94 \%$ \\
\hline A x C & 1 & 0.024 & $0.23 \%$ \\
\hline A x B x C & 1 & 0.020 & $0.19 \%$ \\
\hline Error & 3 & 0.370 & $3.45 \%$ \\
\hline Total & 8 & 10.732 & $100.00 \%$ \\
\hline
\end{tabular}

The regression statistics of this equation (2) are:

- R squared: 96.55\%;

- R squared adjusted: $90.80 \%$;

- and R squared predicted: $76.67 \%$

Another possible optimisation of the equation (1) can be made using Box-Cox transformation with $\lambda=0.5$. In this situation it is resulting the equation (3).

$$
(\text { RaM })^{0.5}=0.000942 \cdot A-0.1194 \cdot B+0.000227 \cdot A \cdot B+0.00269 \cdot A \cdot C-0.000681 \cdot A \cdot B \cdot C
$$

In table 7 it is presented the ANOVA analysis of the regression model (3). 
Table 7. The Variance Analysis ANOVA of the regression model with rounded $\lambda=0.5$.

\begin{tabular}{|c|c|c|c|}
\hline Source & DF (degree of freedom) & SS (sum of square) & Contribution \\
\hline Regression & 5 & 3.171 & $99.76 \%$ \\
\hline A & 1 & 3.139 & $98.74 \%$ \\
\hline B & 1 & 0.013 & $0.43 \%$ \\
\hline A x B & 1 & 0.012 & $0.40 \%$ \\
\hline A x C & 1 & 0.002 & $0.09 \%$ \\
\hline A x B x C & 1 & 0.003 & $0.10 \%$ \\
\hline Error & 3 & 0.007 & $0.24 \%$ \\
\hline Total & 8 & 3.179 & $100 \%$ \\
\hline
\end{tabular}

The regression statistics of this equation (3) are:

- R squared: $99.76 \%$;

- R squared adjusted: $99.37 \%$;

- and R squared predicted: $98.40 \%$

\section{Conclusions}

This research paper presents a methodology to determine the surface roughness obtained under the cutting process parameters influence. The studied cutting process parameters were: the cutting speed, the cutting depth and the feed per tooth. The research method used in this paper was the experiment and the Taguchi design of experiment. After applying the Taguchi method to calculate the influence of the studied cutting process parameters on the surface quality, it was found that the cutting speed is the factor with the greatest influence on the studied response - with $90.35 \%$. According to the influence of the studied cutting process parameters and their interactions, a multiple linear regression model was realised in three different ways to optimise the prediction of the proposed equation:

- The first type of the regression model without transformation it is with $\mathrm{R}$ squared predicted $87.76 \%$,

- The second type of the regression model using rounded $\lambda$ transformation it is with $\mathrm{R}$ squared predicted $76.67 \%$,

- The third type of the regression model using $\lambda=0.5$ transformation it is with $\mathrm{R}$ squared predicted $98.40 \%$.

In this study the best prediction is given by the regression using rounded $\lambda$ transformation, followed by the regression using $\lambda=0.5$ transformation. The lowest degree of prediction is given by the regression with rounded $\lambda$ transformation. Based on the aspects mentioned above, we can concluded that it is possible to improve the prediction of the regression equation that describes the surface roughness in any point of the settled experimental field, using different type of regression and using the same measured values of the surface roughness.

\section{References}

1. A.B. Bontiu Pop, Scientific Bulletin, Serie C, Fascicle: Mechanics, Tribology, Machine Manufacturing Technology ISSN 1224-3264, XXVIII (2014)

2. A. B. Bonţiu Pop, M. Lobonţiu, Applied Mechanics and Materials, 808, 34 ( 2015)

3. A.B. Pop, M.A. Țîțu, IOP Conf. Series: Materials Science and Engineering 161, (2016) 
4. M.A. Țîtu, A.B. Pop, IOP Conf. Series: Materials Science and Engineering 161, (2016)

5. D.C. Montgomery, Design and analysis of experiments, $8^{\text {th }}$ edition, Wiley (2013)

6. M. Țîțu, C. Oprean, A. Boroiu, Cercetarea experimentală aplicată în creșterea calităţii produselor şi serviciilor. Bucureşti: AGIR (2011)

7. N. Medan, Magazine of Hydraulics, Pneumatics, Tribology, Ecology, Sensorics, Mechatronics, 3 (2016)

8. A. B. Bonțiu Pop, Calitatea suprafețelor la așchierea aliajelor de aluminiu cu freze cilindro-frontale, PhD. Thessis. University Baia Mare (2015) 
